\title{
Conversations on dying: giving a family member the last word
}

A s my mother lay on her death bed in hospital, I sit beside her most of each day waiting for a sign of her recovery. She can no longer weight bear; she does not swallow well; her pills are crushed. She has choked on her food, and developed pneumonia. She is delirious, and here we are for antibiotics and an intravenous drip. I focus all of my energy on getting her better.

If you had been there, if you had seen her, you probably would have said, "She's an old and fragile woman, she is likely to die soon." But I never saw that and no one told me. The ten day cycle of antibiotics is complete. Nothing more we can do. We are discharging your Mom out of hospital today. She is now in a palliative state. She can go back to her retirement home.

What do you mean today? She is on a continuous drip, nothing to eat or drink. How will she survive? I haven't spoken with the retirement home. Will they accept her back? Will they be able to look after her? Please wait. I need to figure this out. I wasn't expecting this. Please, not today.

Ms. Chowaniec, we must discharge your Mom at noon today. She is in a palliative state. There's nothing more we can do for her here.

Palliative. I know the word, but what does it mean? From the Latin, palliare, to cloak; to relieve suffering, rather than to provide a cure. How ominous that sounds, to cover over the pain and suffering. How will we conceal her pain and suffering? Is Mom dying?

Well, she is not actively dying; her vital signs are all intact. I'm sure the retirement home will be fine. The nurse will come by and remove the IV.

What does that mean, not actively dying? I must speak to the senior doctor. I find out which room he is in and wait outside. He comes out and heads down the hallway, walking briskly in

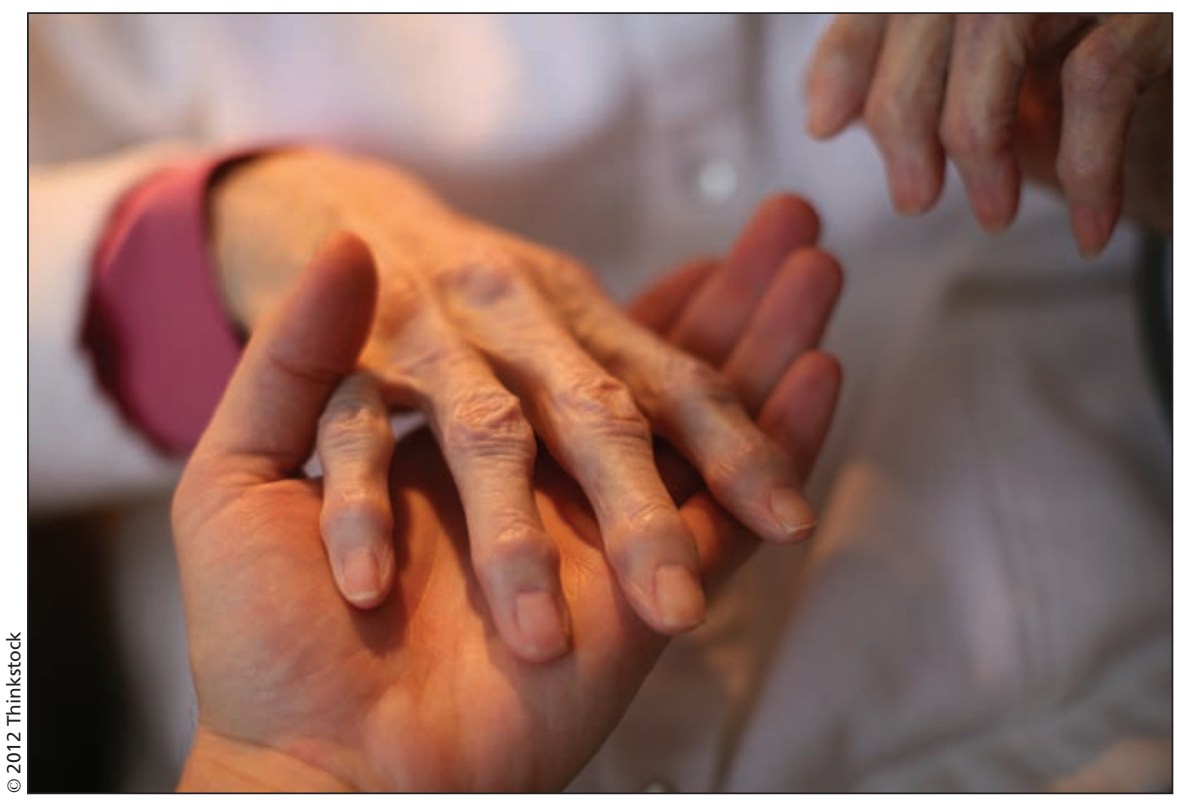

the opposite direction. Oh no, I've missed him. I walk quickly to catch up. I want to run after him. I want to call out his name. Another doctor comes out of a room along the corridor and falls into step beside him. They walk on, talking animatedly. I am embarrassed, practically stalking this man, like a teenager chasing a rock star. I'm screaming inside. I have to talk to you. This is a matter of life and death. It's my Mom. They want to discharge her. She's on an IV. She's barely alive. If you remove it she will die. How can I take her away? How can I look after her? She's safe here. I am lost. I am confused.

In retrospect, I now know, she was dying. Death was imminent and I did not see it. And no one told me. The medical team must have known. Why did no one tell me? Why did you not sit me down and say, "Your Mom has not responded to the antibiotics; she is not eating or drinking on her own. While her vital signs are ok, we do not expect her to recover. We will make the necessary arrangements to have her go home or to a hospice. We will make sure she gets the right care."

We are tremendously resilient as human beings, but we need to know and understand the ground we're standing on, the truth, the facts, in a timely fashion. We need your compassion. We need you to have knowledge and understanding of palliative care. We especially need you to know how to have conversations about dying; those difficult conversations that will help us make the right decisions, and take the right steps forward together.

\section{Claudia Chowaniec PhD CMC \\ Writer and consultant \\ Ottawa, Ont. \\ Tara Tucker MD MEd \\ Palliative care physician \\ Bruyère Continuing Care \\ Ottawa, Ont.}

This article is derived from Chowaniec's forthcoming book, Memoirs of Mourning: Journey from Grief and Loss to Renewal. She also keeps a blog: www.griefshared.com.

CMAJ 2012. DOI:10.1503/cmaj.110795 